\title{
Brain-Derived Neurotrophic Factor Modulates the Development of the Dopaminergic Network in the Rodent Retina
}

\author{
Alessandro Cellerino, ${ }^{1}$ Germán Pinzón-Duarte, ${ }^{1}$ Patrick Carroll,, ${ }^{2}$ and Konrad Kohler ${ }^{1}$ \\ ${ }^{1}$ Division of Experimental Ophthalmology, Department of Neuroophthalmology, University Eye Hospital, D-72076 \\ Tübingen, Germany, and 2Institut National de la Santé et de la Recherche Médicale Unit 382, IBDM, Luminy, 13288 \\ Marseilles 09, France
}

\begin{abstract}
Dopaminergic cells in the retina express the receptor for brainderived neurotrophic factor (BDNF) (Cellerino and Kohler, 1997). To investigate whether BDNF can influence the development of the retinal dopaminergic pathway, we performed intraocular injections of BDNF during the second or third postnatal week and visualized the dopaminergic system with tyrosine hydroxylase $(\mathrm{TH})$ immunohistochemistry. Both regimens of BDNF treatment caused an increase in TH immunoreactivity in stratum 1 and stratum 3 of the inner plexiform layer (IPL). D2 dopamine receptor immunoreactivity, a presynaptic marker of dopaminergic cells (Veruki, 1996), was also increased in stratum 1 and stratum 3 of the inner plexiform layer. These data suggest that BDNF causes sprouting of dopaminergic fibers in the inner plexiform layer. Other neurochemical systems, for example, the cholinergic amacrine cells, remained unaffected. Similar effects were observed after injections of
\end{abstract}

The nerve growth factor (NGF) gene family members-NGF, brain-derived neurotrophic factor (BDNF), neurotrophin-3 (NT3 ), and neurotrophin-4/5 (NT-4/5), collectively named neurotrophins (Ibañez, 1994) — have been largely characterized as neurotrophic factors (for review, see Davies, 1994; Snider, 1994; Lewin and Barde, 1996). In addition to their well described survivalpromoting activity, it is now widely accepted that a predominant action of neurotrophins is related to plasticity of CNS synapses (for review, see Lo, 1995; Thoenen, 1995; Bonhoeffer, 1996; Cellerino and Maffei, 1996). It has been shown, in fact, that neurotrophins influence the morphological maturation of CNS neurons (Cohen-Cory and Fraser, 1995; McAllister et al., 1995, 1997; Marty et al., 1996), the expression of specific neurochemical markers (Nawa et al., 1994; Marty et al., 1996; Rickman and Bowes-Rickman, 1996), and the formation of synaptic contacts (Causing et al., 1997), and they can modulate synaptic efficacy (Le $\beta$ man et al., 1994; Kang and Schuman, 1995; Levine et al., 1995) and activity-dependent plasticity (visual cortex: Maffei et

\footnotetext{
Received Dec. 3, 1997; revised Feb. 9, 1998; accepted Feb. 18, 1998.

This work was supported by European Community Human Capital Mobility Program Grant ERBCHBGCT 940745 (A.C., K.K.). G.P.D. received a fellowship from the Colombian Research Institute of Science and Technology, Colciencias. We are indebted to Hans Thoenen for his support during the initial phase of the analysis of the retina of the BDNF mutant mice and for donating mice for further analysis and some neurotrophins used in pilot experiments. Gudrun Härer provided very skillful technical assistance in histological preparations, and Blanca Aurora ArangoGonzález performed the photographic work and gave us valuable help in quantifying bouton densities.

Correspondence should be addressed to Alessandro Cellerino, Istituto di Neurofisiologia del Consiglio Nazionale delle Ricerche, via San Zeno 51, I-56127, Pisa, Italy.

Copyright (ㄷ) 1998 Society for Neuroscience $\quad 0270-6474 / 98 / 183351-12 \$ 05.00 / 0$
}

neurotrophin-3 and neurotrophin-4, but not nerve growth factor. Analysis of whole-mounted $\mathrm{TH}$-immunolabeled retinae revealed hypertrophy of dopaminergic cells $(+41 \%$ in soma areas; $p<0.01$ ) and an increase of labeled dopaminergic varicosities in stratum 1 of the IPL $(+51 \% ; p<0.01)$ after BDNF treatment. The opposite was observed in mice homozygous for a null mutation of the bdnf gene: dopaminergic cells were atrophic $(-22.5 \%$ in soma areas; $p<0.05)$, and the density of $\mathrm{TH}$-positive varicosities in stratum 1 was reduced $(57 \%$; $p<$ 0.01). We conclude that BDNF controls the development of the retinal dopaminergic network and may be particularly important in determining the density of dopaminergic innervation in the retina.

Key words: neurotrophin; growth factor; retina; inner plexiform layer; amacrine neuron; development; synaptogenesis; BDNF knock-out mouse; Parkinson's disease

al., 1992; Domenici et al., 1994; Gu et al., 1994; Cabelli et al., 1995, 1997; Galuske et al., 1996; hippocampus: Korte et al., 1995; Figurov et al., 1996; Korte et al., 1996; Patterson et al., 1996).

The mammalian retina is probably the region of the vertebrate brain in which local microcircuits have been described best (Sterling, 1990; Wässle and Boycott, 1991; Kolb, 1994). Because detailed knowledge of its organization is available, the retina provides a convenient system for investigating the effects of neurotrophins on the development of specific CNS connections. The morphology and physiology of one specific retinal neuron, the retinal dopaminergic cell, has been described in great detail (for review, see Nguyen-Legrós, 1988; Witkowsky and Schütte, 1991). In mammals, dopaminergic cells are a sparse population of widefield amacrine (and interplexiform cells) that receive input from cone bipolar cells (Hokoç and Mariani, 1987) and extend processes at the border between the inner nuclear layer and the inner plexiform layer (Voigt and Wässle, 1987; Dacey, 1990). Dopaminergic processes establish synapses mostly onto the soma of a specific type of interneuron in the rod pathway, the glycinergic AII amacrine cell (Voigt and Wässle, 1987), and are restricted to the border between the inner plexiform layer and the inner nuclear layer (stratum 1). Dopamine release is increased by light, and this light-induced release of dopamine is believed to play a role in the inhibitory mechanisms underlying light adaptation (Witkowsky and Dearry, 1991). In a previous work, we reported that dopaminergic neurons in the vertebrate retina express the BDNF receptor TrkB (Barbacid, 1994) and suggested that BDNF may act on dopaminergic retinal neurons (Cellerino and Kohler, 1997). The present study tested this hypothesis by examining the 


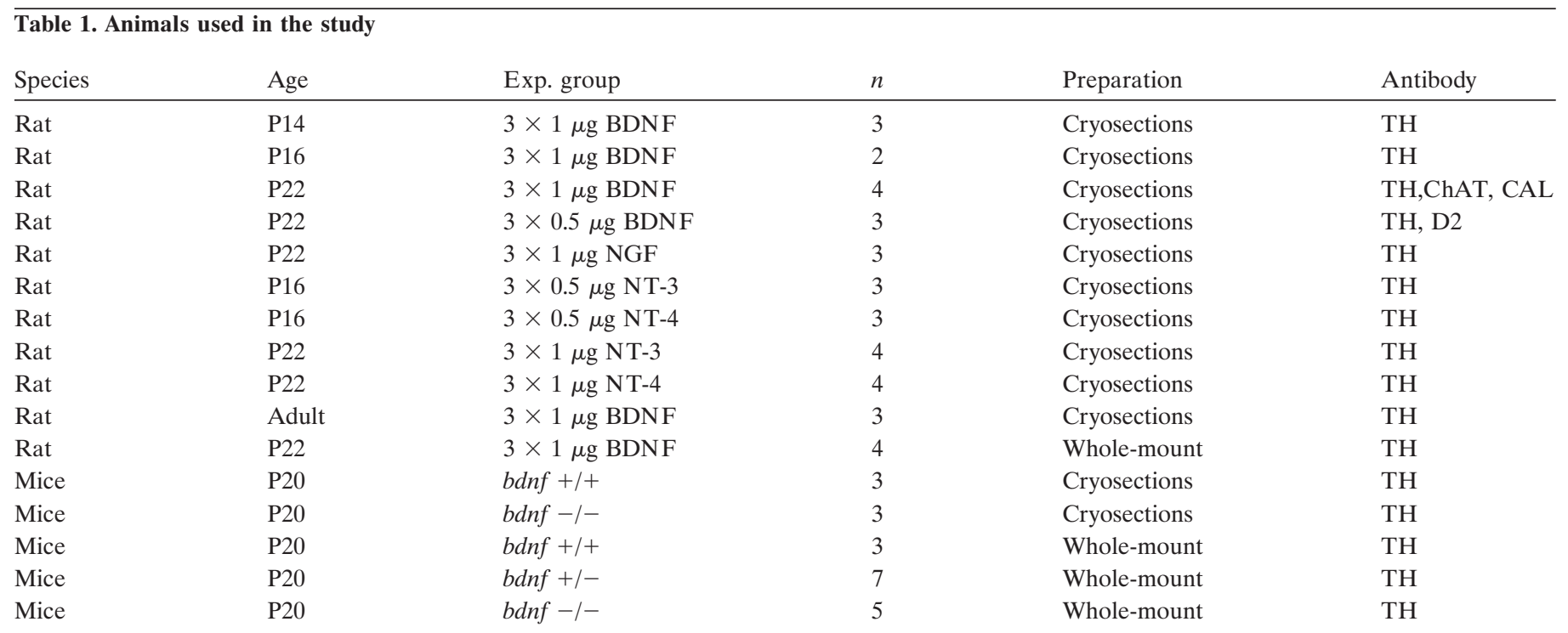

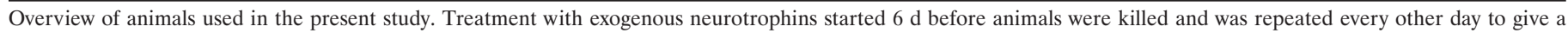

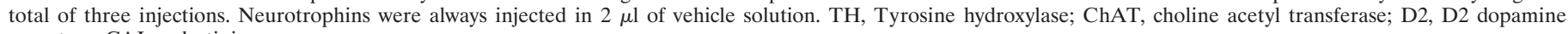
receptors; CAL, calretinin.

effects of the four neurotrophins on the development of dopaminergic innervation in the rat retina after intraocular injection. In addition, dopaminergic neurons were examined in mice homozygous for a null mutation of the bdnf gene.

Some of these data were published previously (Cellerino et al., 1997).

\section{MATERIALS AND METHODS}

$B D N F$ injections. Rat pups were anesthetized with ether. In pups younger than postnatal day (P) 15, the eyelids were opened gently with a fine forceps. One microgram of human recombinant BDNF, human recombinant NT-3, human recombinant NT-4, or mouse $\beta$-NGF (Alomone Laboratories) in $2 \mu \mathrm{l}$ of $0.1 \%$ bovine serum albumin (BSA) in sterile PBS was injected with a fine glass microelectrode through the sclera at the level of the temporal peripheral retina. The other eye received $2 \mu \mathrm{l}$ of vehicle solution. The whole procedure required only a few minutes and was completed before the animals recovered from the anesthesia. Surgical procedures were performed according to the German law and the guidelines of the Association for Research in Vision and Ophthalmology (ARVO). For the complete list of animals used in the present study see Table 1.

bdnf $(-/-)$ mice. The generation of the line of bdnf null mutant mice used in the present study has been described elsewhere (Korte et al., 1995). Homozygous mutants were obtained by crossing heterozygous mutant mice, and animals were genotyped by performing PCR on genomic DNA obtained from pieces of tails using standard molecular biology techniques.

Immunohistochemistry on cryosections. To prepare cryostat sections, animals were anesthetized with ether and killed by cervical dislocation (adult rats were killed with an overdose of ether). The eyes were enucleated, the anterior poles and lens were removed, and the eye cups were fixed for $1 \mathrm{hr}$ in $4 \%$ paraformaldehyde (PFA) in $100 \mathrm{~mm}$ phosphate buffer, $\mathrm{pH} 7.4$ (PB). The fixed eye cups were washed in $\mathrm{PB}$ several times and then cryoprotected in $30 \%$ sucrose in $\mathrm{PB}$ at $4^{\circ} \mathrm{C}$ overnight. Eye cups were then embedded in cryomatrix (Tissuetek, Reichart-Jung, Nußloch, Germany) and frozen in liquid nitrogen. Radial sections $(14-16 \mu \mathrm{m})$ were cut on a cryostat (Reichart-Jung), collected onto gelatin-coated slides, air-dried, and stored at $-20^{\circ} \mathrm{C}$ until further processing.

Slides were thawed and washed three times in PBS (50 mM), pH 7.4, and then incubated in a solution of PBS with 20\% NGS and $0.03 \%$ Triton $\mathrm{X}-100$ (PBST) for 1-2 hr. Sections were then incubated with one of the following antibodies: mouse anti-TH (Incstar, Stillwater, MN) 1:3000, rabbit anti-D2 (Chemicon, Temecula, CA) 1:1000, rabbit anti-calretinin (Chemicon) 1:300, or mouse anti-ChAT (Chemicon) 1:300 in PBST at $4^{\circ} \mathrm{C}$ overnight. Immunoreaction was detected using $\mathrm{Cy} 3$-labeled goat anti-rabbit or anti-mouse serum (Rockland, Gilbertsville, PA) diluted 1:1000. Sections were washed three times in PBS and then coverslipped with 9:1 glycerol/PBS and stored at $-20^{\circ} \mathrm{C}$.

Controls were performed by omitting the primary antibody or replacing it with PBS.

Whole-mount immunohistochemistry. Animals were anesthetized with ether and killed by cervical dislocation. The eyes were enucleated, the anterior chamber was removed, and the eyecups were fixed for $30 \mathrm{~min}$ in $2 \%$ PFA in PBS. Retinae were dissected out, four radial cuts were made to allow flattening, and the retinae were fixed at $4^{\circ} \mathrm{C}$ for $2 \mathrm{hr}$ in $4 \%$ PFA in PBS between two microscopic slides with a spacer interposed to prevent damage. Defattening (Versaux-Botteri and Nguyen-Legrós, 1986) was used to improve antibody penetration. The retinae were dehydrated in ascending ethanol concentrations $(50,70,85,90,96$, and $100 \%$ ), incubated for $1 \mathrm{hr}$ at room temperature in xylene, rehydrated in a descending alcohol series, and washed three times in PBS. Retinae were then incubated overnight in $20 \%$ NGS in PBS with $0.3 \%$ Triton $\mathrm{X}$-100 containing 1:3000 mouse anti-TH (Incstar) for $3 \mathrm{~d}$ at $4^{\circ} \mathrm{C}$ with continuous agitation and for $1 \mathrm{~d}$ at $4^{\circ} \mathrm{C}$ in the same buffer containing a 1:1000 dilution of Cy-3 labeled goat anti-rabbit (Rockland Labs) with continuous agitation. Retinae were mounted flat, with the retinal ganglion cell layer oriented upward, and coverslipped with a 9:1 mixture of glycerol/PBS. The slides were stored at $-20^{\circ} \mathrm{C}$ between examinations.

Morphometric analysis. Labeled cells were counted directly at the microscope with a $20 \times$ objective (type I cells) or $40 \times$ oil immersion objective (type II cells) using an Olympus AX-70 microscope. For each mouse retina the sample consisted of five fields of $0.4 \mathrm{~mm}^{2}$ : one in the center, adjacent to the optic nerve head, and one approximately in the middle of the retinal radius in each retinal quadrant. For each rat retina, the sample consisted of two $0.4 \mathrm{~mm}^{2}\left(0.1 \mathrm{~mm}^{2}\right.$ for type II cells) fields in each retinal quadrant: one near the retinal center and one approximately at the middle of the retinal radius.

The number of primary dendrites was determined directly at the microscope by examining 20-30 cells for each retina from the same region in which cells had been counted. Care was taken to sample approximately the same number of cells from each retinal quadrant.

Mean cell size was estimated by photographing the cells with a $40 \times$ oil immersion objective, projecting them at a final magnification of $1000 \times$, and tracing their outlines. These drawings were scanned and analyzed with NIH Image 1.44 . The sampled areas were $1.2-2 \mathrm{~mm}^{2}$ in mice and $1.6-3.2 \mathrm{~mm}^{2}$ in rats.

To quantify the density of TH-immunopositive varicosities, several fields were photographed in the central retina with the focus in stratum 1 using a $40 \times$ oil immersion objective with small numerical aperture. In this way, all TH-positive varicosities were contained on a single focal plane. Pictures were printed at a final magnification of $1000 \times$ on high- 


\section{P14}



CONTROL

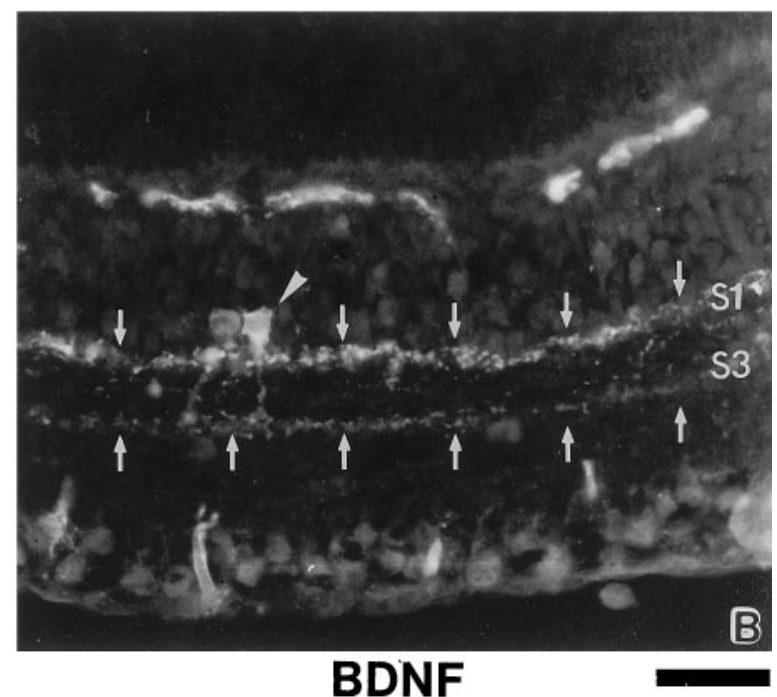

\section{P22}

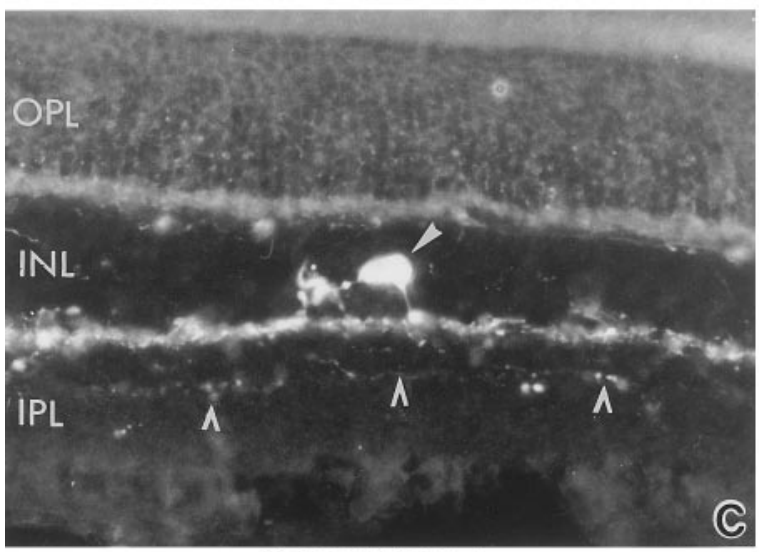

CONTROL

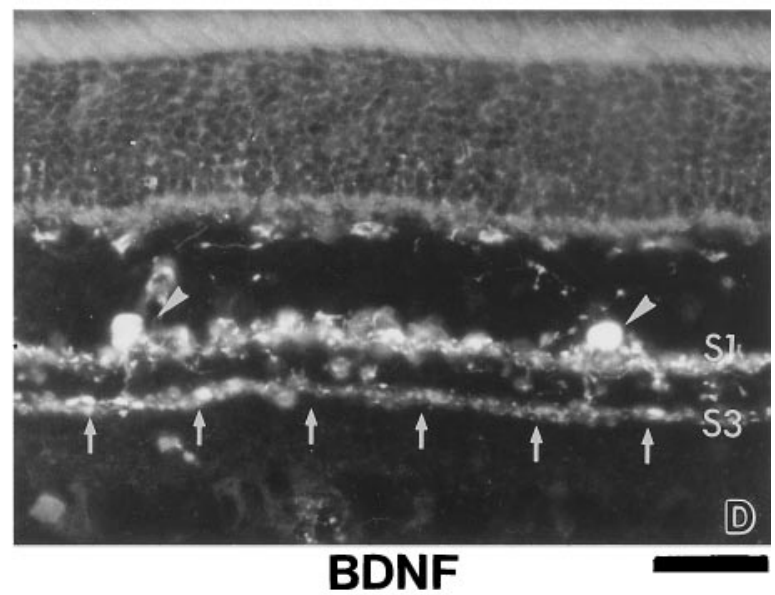

Figure 1. Effects of endogenous BDNF treatment on the development of retinal dopaminergic innervation (TH immunohistochemistry). To prevent the ventrodorsal gradient of retinal dopaminergic innervation (Nguyen-Legrós, 1988) from confounding interpretation of the data, only pictures obtained from the central retina were compared. $A$, Control P14 retina. A dopaminergic neuron is indicated by an arrowhead. A few TH-positive varicosities are seen in sublamina s1 (open arrowheads). B, The retina contralateral to the retina shown in $A$ that received three injections of $1 \mu \mathrm{g}$ of BDNF on P8, P10, and P12. Dopaminergic neurons are indicated by arrowheads. Labeling is continuous in lamina s1 and less intense in lamina s3 (small arrows). $C$, Control P22 retina. A dopaminergic neuron is indicated by an arrowhead. A few TH-positive varicosities are seen in lamina s3 (open arrowheads). D, The retina contralateral to the retina shown in $C$ that received three injections of $1 \mu \mathrm{g}$ of BDNF at P16, P18, and P20. Dopaminergic neurons are indicated by arrowheads. A continuous labeling is observed in lamina s3 (small arrows). $O N L$, Outer nuclear layer; $I N L$, inner nuclear layer; $I P L$, inner plexiform layer. Scale bar, $35 \mu \mathrm{m}$.

contrast photographic paper. The sampling area was represented by a box of $10,000-20,000 \mu \mathrm{m}^{2}$ where labeled varicosities were all contained in the plane of focus. For each retina, four to six of these areas were counted, and at least one area was selected for each retinal quadrant.

All measurements were performed on coded preparations or pictures by researchers who were unaware of their experimental history.

Differences between experimental and control groups were tested statistically with the paired Student's $t$ test (BDNF-treated rats) or unpaired Student's $t$ test, with independent variabilities in the two samples (bdnf mutant mice) using Microsoft Excel.

\section{RESULTS}

The retinal dopaminergic network in BDNF-treated rats Dopaminergic neurons first appear in the rat retina between P3 and P5 (Nguyen-Legrós et al., 1983; Mitrofanis et al., 1988).
TH-positive fibers innervating stratum 1 of the inner plexiform layer (IPL) are first detected at the beginning of the second postnatal week and progressively grow to form a continuous plexus of innervation that is not completed before the end of the third postnatal week (Mitrofantis et al., 1988). This period (P5P21) largely corresponds to the phase of synaptogenesis for amacrine neurons in the rat retina (Horsburgh and Sefton, 1987).

We decided to investigate the effects of BDNF on the development of the dopaminergic network during the second or third postnatal week. We injected BDNF $(0.5-1 \mu \mathrm{g})$ into the eye in rat pups, followed by one additional injection every other day. The other eye received vehicle injections and served as control. The animals were killed on the seventh day. This regimen was suffi- 


\section{D2 receptors}



CONTROL



BDNF

Figure 2. Effects of BDNF injections on D2 receptor immunoreactivity. To prevent the ventrodorsal gradient of retinal dopaminergic innervation (Nguyen-Legrós, 1988) from confounding interpretation of the data, only pictures obtained from the central retina were compared. $A$, Control $\mathrm{P} 22$ retina. The D2-labeled dopaminergic plexus is indicated by small arrows. The framed box is magnified in the top left corner of the picture to show a detail of the thin, D2-labeled plexus. $B$, Contralateral retina that received three injections of $0.5 \mu \mathrm{g}$ of BDNF at P16, P18, and P20. The D2-labeled plexus in stratum 1 is indicated by small arrows; the plexus in stratum 3 is indicated by open arrowheads. The framed box is magnified in the top right corner of the picture. Scale bar, $50 \mu \mathrm{m}$.

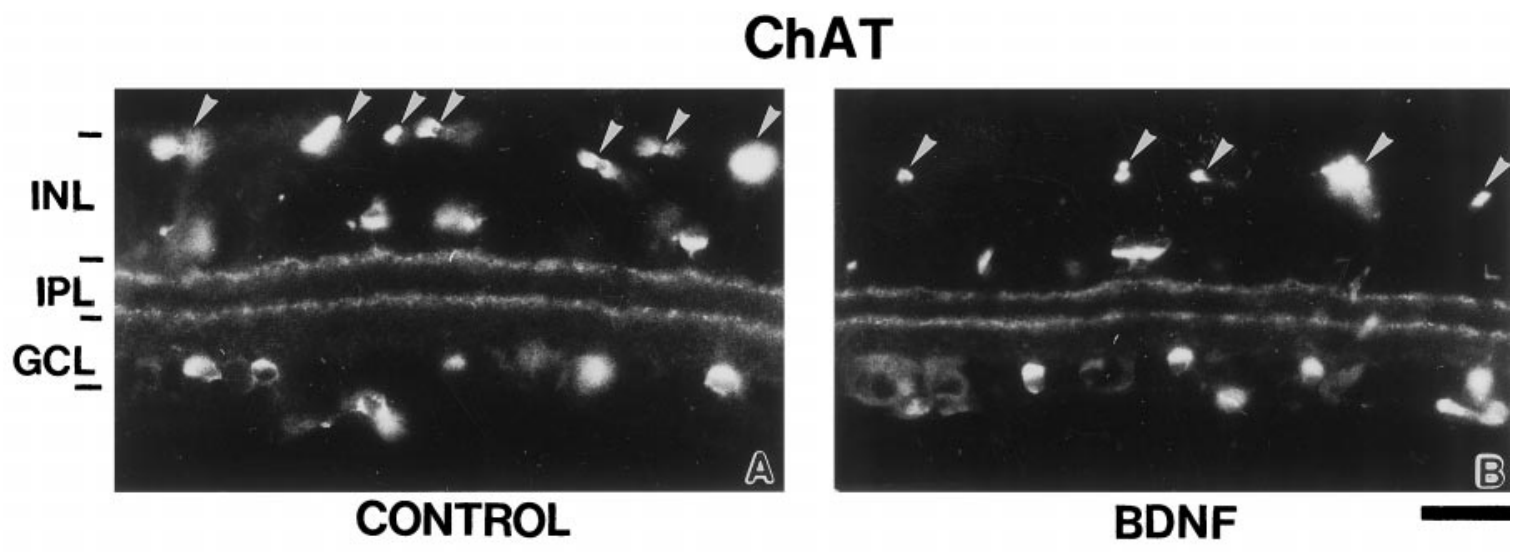

\section{Calretinin}


Figure 3. Effects of BDNF injections on the development of choline acetyl transferase and calretinin immunoreactivity. The sections illustrated in this figure were obtained from the animal whose retinal dopaminergic system is shown in Figure $1 C, D$. $A$, Control P22 retina. Choline acetyl transferase immunoreactivity (ChAT) revealed with a monoclonal anti-ChAT antibody. Unspecific reaction of the secondary antibody with blood vessels is indicated by arrowheads. Two bands of ChAT immunoreactivity are clearly visible in the middle of the IPL. $B$, The retina contralateral to the retina shown in $A$, which received three injections of $1 \mu \mathrm{g}$ of BDNF at P16, P18, and P20. No differences are visible. $C$, Control P22 retina (calretinin immunoreactivity). Three bands of punctate calretinin immunoreactivity are clearly visible in the IPL. Numerous cells are visible in both the INL and GCL. $D$, The retina contralateral to the retina shown in $A$, which received three injections of $1 \mu \mathrm{g} \mathrm{BDNF}$ at P16, P18, and P20. No differences are visible. ONL, Outer nuclear layer; $I N L$, inner nuclear layer; $I P L$, inner plexiform layer. Scale bar, $35 \mu \mathrm{m}$. 


\section{P16}

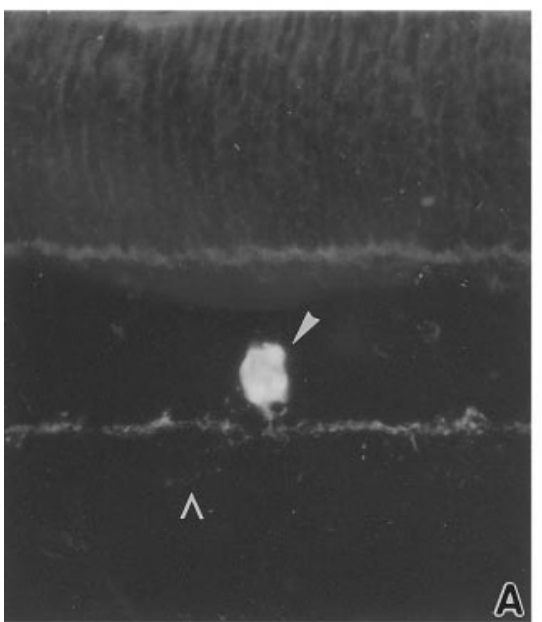

CONTROL

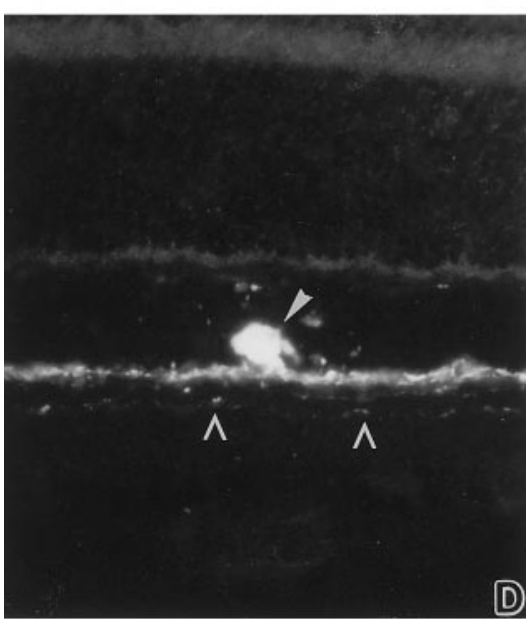

CONTROL

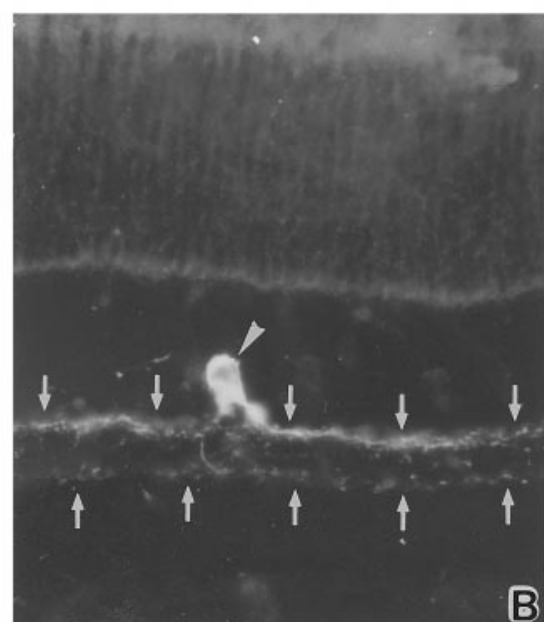

NT-3

P22

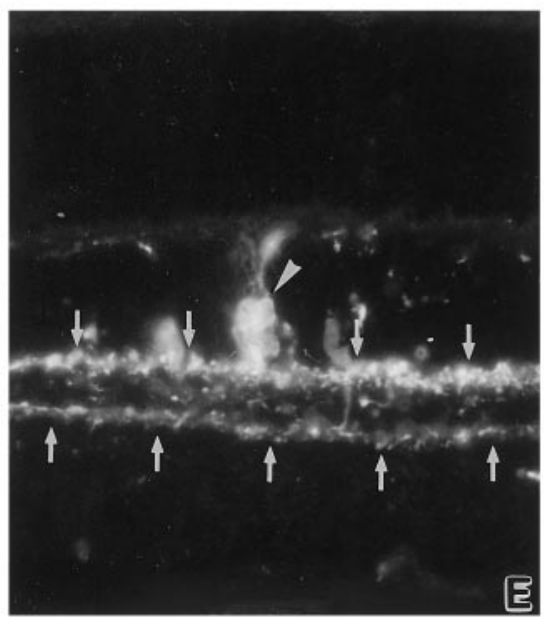

NT-3

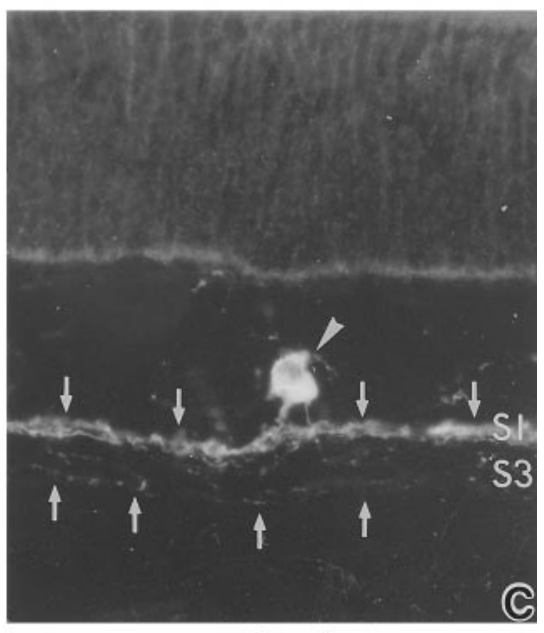

NT-4

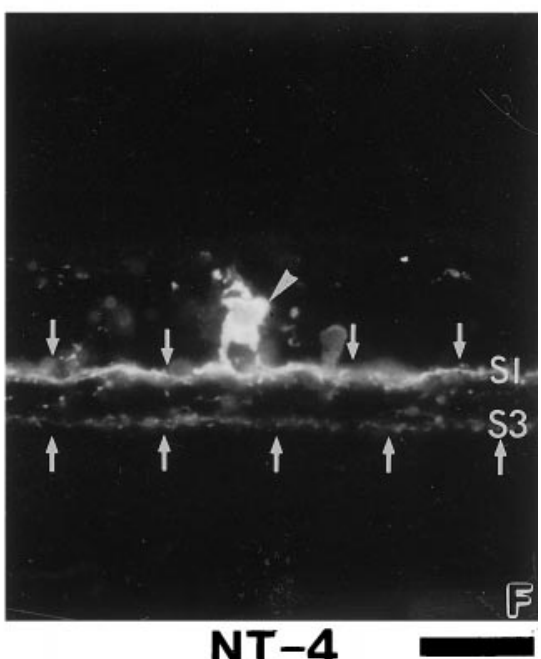

Figure 4. Effects of different neurotrophins on the development of dopaminergic innervation. To prevent the ventrodorsal gradient of retinal dopaminergic innervation (Nguyen-Legrós, 1988) from confounding interpretation of the data, only pictures obtained from the central retina were compared. Radial sections are shown. A, Control P16 retina. A dopaminergic neuron is indicated by an arrowhead. Very few processes are seen in lamina s3 (arrowhead). B, A P16 retina that received three injections of $0.5 \mu \mathrm{g}$ of NT-3 at P10, P12, and P14. A dopaminergic neuron is indicated by an arrowhead. Labeling is continuous in lamina s1 and less intense in lamina s3 (small arrows). $C$, A P16 retina that received three injections of $0.5 \mu \mathrm{g}$ of NT-4 at P 10, P12, and P14. A dopaminergic neuron is indicated by an arrowhead. Labeling is continuous in lamina s1 and less intense in lamina s3 (small arrows). D, Control P22 retina. A dopaminergic neuron is indicated by an arrowhead. A few processes are seen in lamina s3 (arrowhead). E, A P22 retina that received three injections of $1 \mu \mathrm{g}$ of NT-3 at P16, P18, and P20. A dopaminergic neuron is indicated by an arrowhead. Continuous labeling is observed in lamina $\mathrm{s} 3$ (small arrows); the labeling in lamina $\mathrm{s} 1$ also seems to be increased (small arrows). $F$, A P22 retina that received three injections of $1 \mu \mathrm{g}$ of NT-4 at P16, P18, and P20. A dopaminergic neuron is indicated by an arrowhead. Continuous labeling is observed in lamina s3 (small arrows). Scale bar, $35 \mu \mathrm{m}$.

cient to persistently increase BDNF levels in the retina, as demonstrated by BDNF immunohistochemistry (data not shown). No differences were noticed between animals treated with 1 or $0.5 \mu \mathrm{g}$ of BDNF.

A first set of rats received the first injection on P8 and were killed on P14 $(n=3)$. In accordance with previously published data (Mitrofanis et al., 1988), the retinal dopaminergic system appeared immature in the control retinae at P14. Somata of dopaminergic cells were labeled, but the plexus of dopaminergic fibers localized in stratum 1 (s1) of the IPL, close to the border of the inner nuclear layer (INL), was visibly less dense than in adults (Fig. 1 $A$ ). In contrast, a continuous, dense dopaminergic plexus was observed in the BDNF-treated retinae (Fig. $1 B$ ). In addition to the TH-positive plexus in s1, a more lightly labeled plexus of dopaminergic innervation was observed in the middle of the IPL (s3). Similar effects were observed in two rats that received the first BDNF injection on P10 and were killed on P16 (data not shown).

In a second set of experiments, rat pups $(n=4)$ received the first dose of BDNF on P16, and the effects of exogenous BDNF 


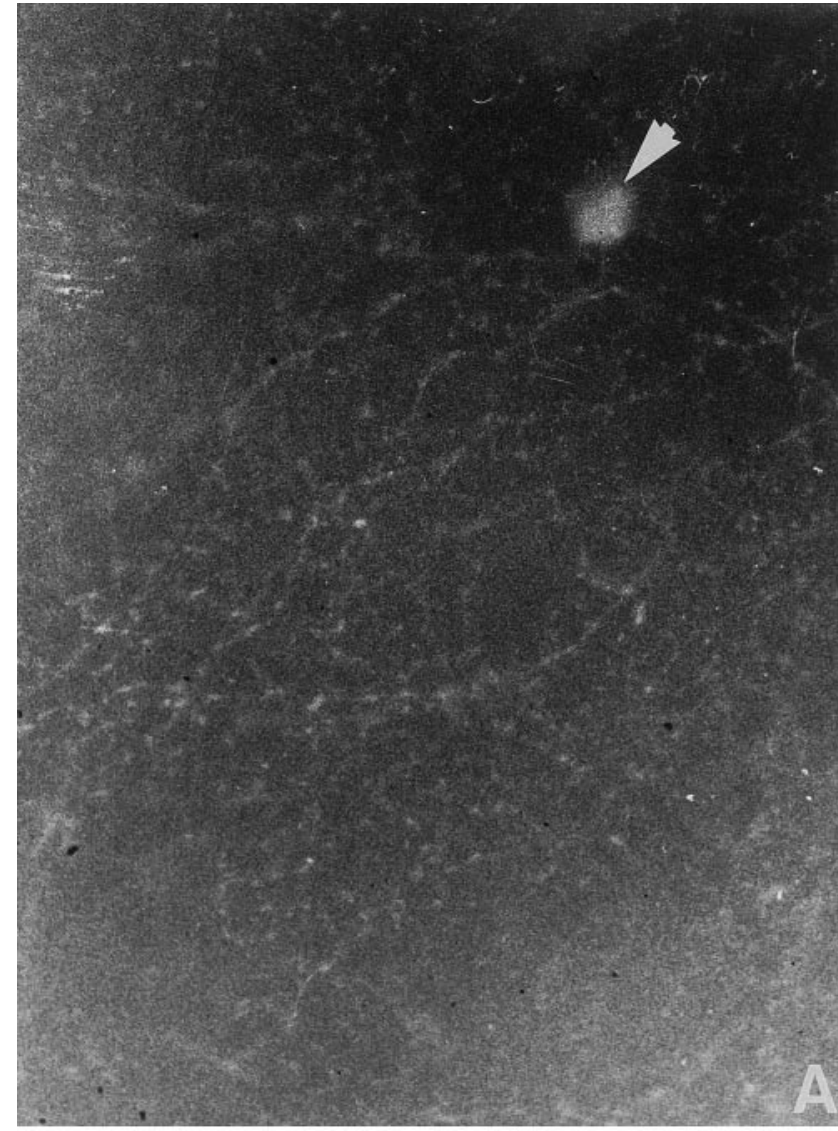

CONTROL

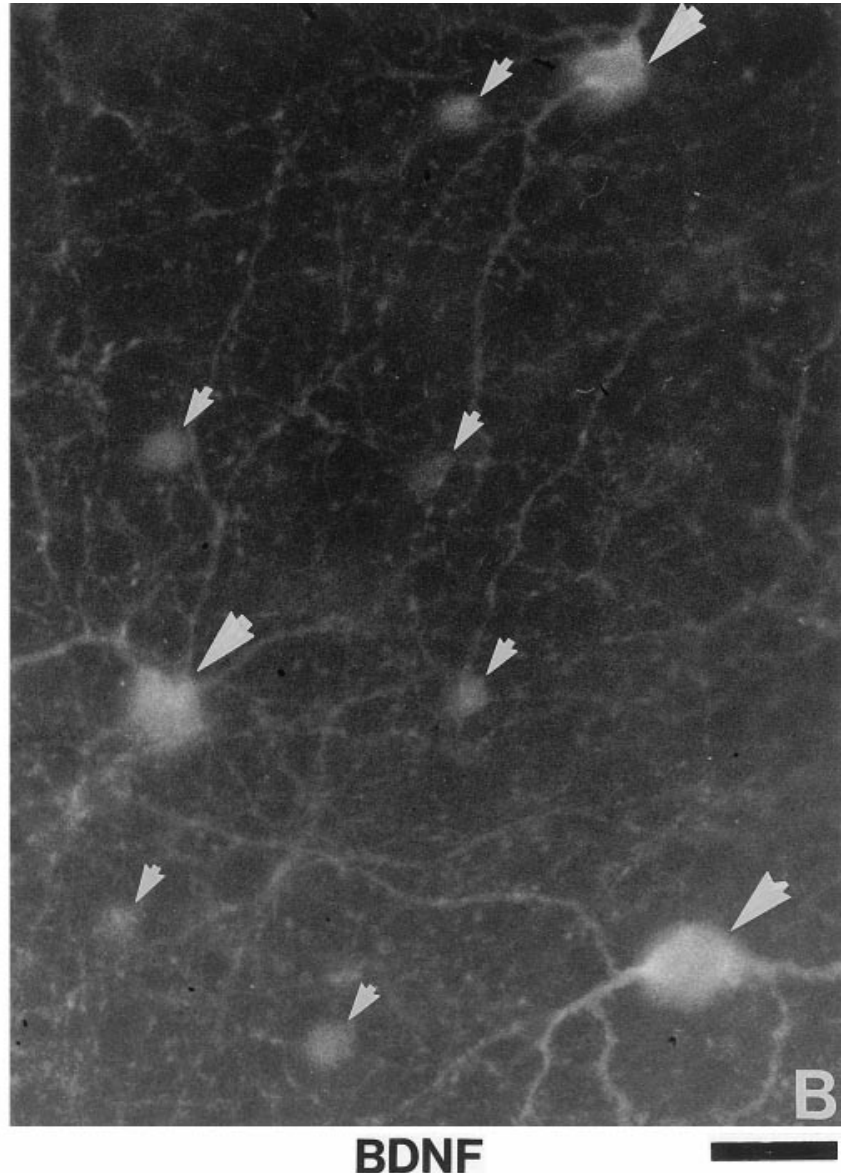

Figure 5. Effects of BDNF injections on TH immunoreactivity (whole-mount preparations). Focus is at the level of stratum 1, central retina. The cell bodies of TH-positive cells are in the inner plexiform layer and therefore out of focus. $A$, Control P22 retina. A type I dopaminergic neuron is indicated by a large arrowhead; its dendritic arborization is out of focus. $B$, The retina contralateral to the retina shown in $A$ that received three injections of $1 \mu \mathrm{g}$ BDNF at P16, P18, and P20. Type I dopaminergic neurons are indicated by big arrowheads; type II dopaminergic neurons are indicated by small arrowheads. Scale bar, $22 \mu \mathrm{m}$.

were examined at P22. At P22, the retinal dopaminergic system is more mature, and a continuous plexus of dopaminergic innervation is visible in s1 (Fig. 1C) (Mitrofanis et al., 1988). In BDNFtreated retinae, this dopaminergic plexus appeared more dense, but the difference between BDNF-injected and control eyes was not as striking as in younger animals. A striking difference was the presence of a continuous, brightly labeled plexus of dopaminergic innervation in $\mathrm{s} 3$ of the BDNF-treated retinae (Fig. 1D). In control retinae, some faint labeling was observed in $\mathrm{s} 3$ as well; it consisted of thin, sparse, isolated processes with gaps of variable size between one labeled process and the other. S3 labeling was more dense in the dorsal retina and almost absent in the ventral retina, as already described (Nguyen-Legrós, 1988). By contrast, a continuous, brightly labeled band was visible in s3 in BDNFtreated retinae. This labeled band ran without interruption from the dorsal end to the ventral end of the retina.

Some dopaminergic cells in rodents are interplexiform; i.e., in addition to the usual arborization in the IPL, they extend processes vitreally toward the outer plexiform layer (OPL) (NguyenLegrós, 1988; Witkowsky and Schütte, 1991). These processes are very sparse in control animals, whereas their number was visibly increased in BDNF-treated animals (not shown). This effect was difficult to quantify, however, and a detailed analysis of the action of neurotrophins on the development of interplexiform cells will be the subject of a future study.
Visible effects were observed in neither the IPL nor the OPL if the same regimen of BDNF intraocular injections was performed in adult animals $(n=3$; data not shown).

We also analyzed the expression of D2 dopamine receptors in BDNF-treated retinae. Pharmacological (for review, see Witkowsky and Dearry, 1991) and immunohistochemical studies (Veruki, 1996) have shown that dopaminergic neurons use D2 receptors as presynaptic autoreceptors. Therefore, D2 immunoreactivity provides an independent marker for studying retinal dopaminergic innervation. In control retinae, D2 immunoreactivity is diffusely distributed in the IPL, except that in s1 a very thin row of brighter varicosities standing out against the diff use labeling of the IPL is seen (Fig. $2 A$ ). This band of more intense labeling corresponds to the plexus of dopaminergic innervation (Veruki, 1996). D2 immunoreactivity in s1 is visibly enhanced after BDNF treatment. In addition, a labeled band standing out against the diff use IPL labeling is faintly visible in s3 (Fig. 2B). There are no apparent changes in the diffuse staining in the IPL. These data are consistent with the idea that BDNF increases the density of dopaminergic terminals.

To test whether an exogenous supply of BDNF disturbs the lamina-specific organization of all neurochemically defined connections in the IPL, we examined immunoreactivity for calretinin and choline acetyl transferase (ChAT) in the same retinae in which changes in the organization of the dopaminergic inner- 

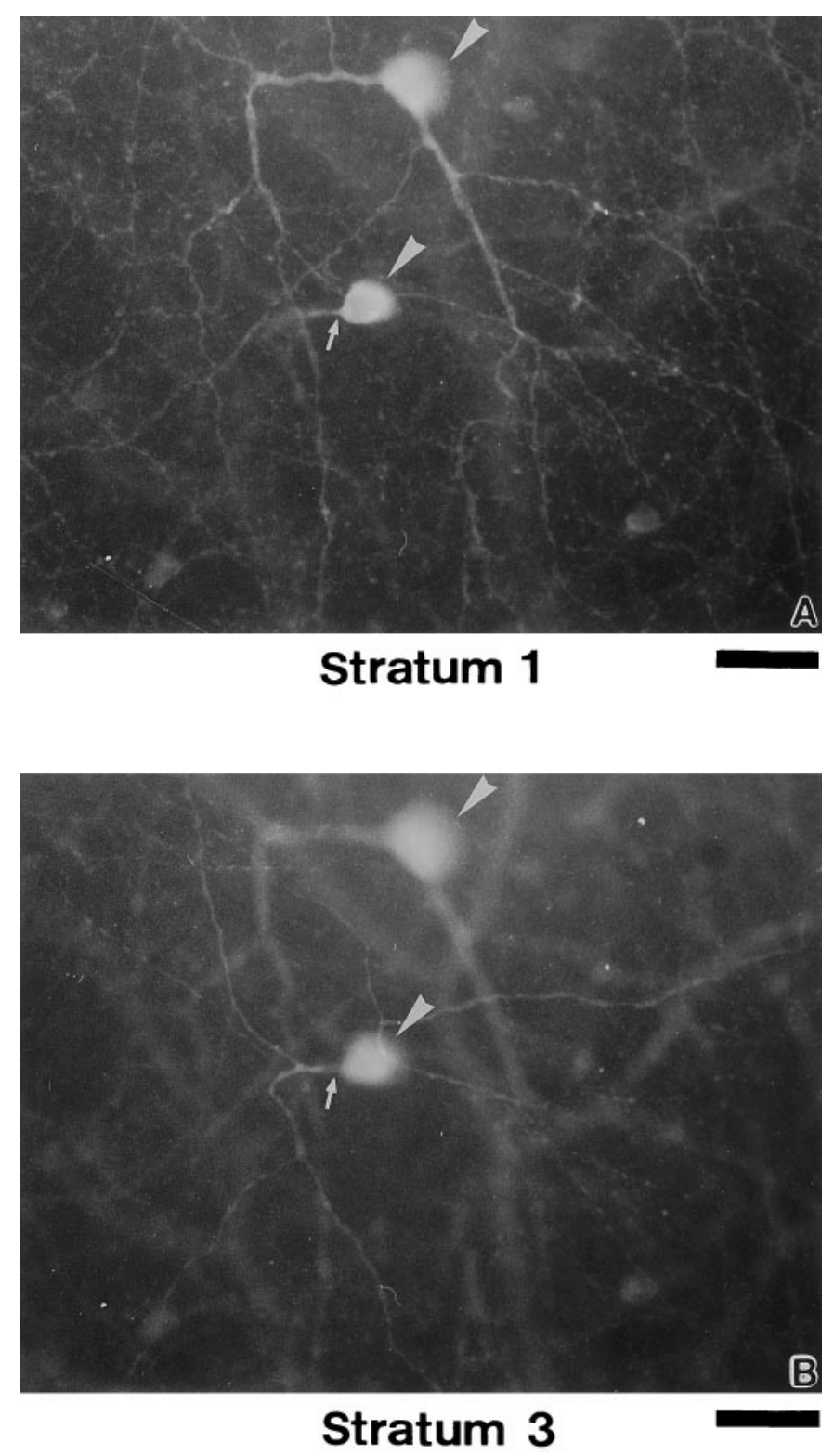

Figure 6. Detail of the plexus of dopaminergic innervation in stratum 3 in a BDNF-treated retina. $A$, Focus in stratum 1 . Cell bodies of type I dopaminergic cells are indicated by arrowheads. Note the process emerging from the cell at the bottom of the picture (small arrow). In $B$, the same process can be traced as it ramifies in stratum 3. Scale bar, $35 \mu \mathrm{m}$.

vation were evident. No apparent differences were noticed in the lamina-specific distribution of calretinin- or ChATimmunoreactive processes in the IPL of treated and control retinae (Fig. 3).

\section{Effects of NGF, NT-3, and NT-4}

We investigated whether neurotrophins other than BDNF can influence dopaminergic neurons in the retina. NGF, NT-3, or NT-4 were administered during either the second or third postnatal week following the same protocol used for BDNF. NGF injections did not cause visible changes in the pattern of dopaminergic innervation ( $n=3$; data not shown). Injections of NT-3 during the second $(n=3)$ or third postnatal week $(n=4)$ caused a clear increase of TH immunolabeling in s1 and s3 (Fig. 4B,E). Injections of NT-4 during the second $(n=3)$ or third postnatal week $(n=4)$ also caused increased TH labeling in s1 and s3 (Fig. $4 C, F)$. NT-4 effects, however, were somewhat more variable and less pronounced than the effects of NT-3.

\section{Quantification of BDNF effects in whole-mount preparations}

Dopaminergic neurons are very sparse (usually only two to five cells are visible per section), and it is difficult to quantify cell density and size in radial sections because of the very limited sample size. To provide a quantitative basis for the differences observed in the organization of the dopaminergic network after BDNF injections, rat pups $(n=4)$ received BDNF by intraocular injections, starting at P16, according to the described protocol. The animals were killed at P22, and BDNF-treated retinae and the contralateral control retinae were processed for whole-mount TH immunohistochemistry.

Generally, two morphological classes of dopaminergic cells can be differentiated in adult mammals: sparse cells with large somata that display intense $\mathrm{TH}$ immunoreactivity, and a more numerous population of smaller cells with light $\mathrm{TH}$ immunoreactivity. Mariani and Hokoç (1988) named the former type I and the latter type II dopaminergic neurons. Another peculiar characteristic of adult dopaminergic innervation, particularly striking in flatmount preparations, is its organization into pericellular baskets surrounding the somata of amacrine neurons (mostly glycinergic AII amacrine cells) located at the vitreal border of the INL (Voigt and Wässle, 1987). We observed no type II dopaminergic neurons in one of the flat-mounted P22 retinae obtained from control eyes. In the other three, type II cells were encountered only occasionally. These cells were labeled very weakly, and the cellular contours were not clearly distinguishable. No pericellular baskets were evident at P22 (Fig. 5). Flat-mounted BDNF-treated retinae were visibly different from the control retinae. Type II dopaminergic neurons could be readily seen. In addition, Type I dopaminergic cells appeared hypertrophic; their dendritic arborization was more intensely labeled, and TH-positive varicosities seemed to be more numerous. The presence of a profuse TH-positive plexus in s3 of BDNF-treated retinae was evident in the whole-mount preparation. Processes in s3 could be often traced back to the cell of origin, which was always a type I cell (Fig. 6).

Statistical analysis of morphological parameters in flatmounted retinae demonstrated significant differences between control and BDNF-treated retinae. The density of labeled type II dopaminergic neurons was increased approximately sixfold $(p<$ 0.001 ), whereas the density of type I dopaminergic neurons did not change. The soma area of type I dopaminergic neurons was increased by $41 \%(p<0.01)$, and the density of TH-positive varicosities in $\mathrm{s} 1$ was increased by $51 \%(p<0.01)$. These quantitative data are summarized in Figure 7. The mean number of primary dendrites also increased from 3 to $3.6(p<0.01)$. The widespread overlap between the dendritic arbors of adjacent type I dopaminergic neurons precluded a more detailed analysis of their dendritic complexity.

\section{The retinal dopaminergic network in bdnf-/- mice}

To test whether the effects observed after postnatal treatment with BDNF reflected a physiological action of BDNF on retinal dopaminergic neurons, we analyzed $\mathrm{TH}$ immunoreactivity in mice with a targeted deletion of the $b d n f$ gene. Retinae from P20 $b d n f-/-$ mouse pups $(n=5)$ obtained by crossing $b d n f+/-$ mice were processed for whole-mount TH immunohistochemistry. 
Figure 7. Quantitative analysis of the effects of intraocular BDNF injection during the third postnatal week on the development of dopaminergic neurons. $A$, Density of type I dopaminergic cells expressed as number of cells per square millimeter. See the Materials and Methods for details of the sampling method. $C O N$ indicates the control eye, and $B D N F$ indicates the BDNF-treated eye. $B$, Density of type II dopaminergic cells expressed as number of cells per square millimeter. See Materials and Methods for details of the sampling method. $C O N$ indicates the control eye, and $B D N F$ indicates the BDNF-treated eye. $C$, Soma area of type I dopaminergic neurons. See Materials and Methods for details of the sampling method. $C O N$ indicates the control eye, and $B D N F$ indicates the BDNF-treated eye. $D$, Density of TH-positive varicosities in stratum 1 of the inner plexiform layer expressed as number of varicosities per square millimeter. See Materials and Methods for details of the sampling method. $C O N$ indicates the control eye, and $B D N F$ indicates the BDNF-treated eye. Four different littermates were analyzed, and the values in the BDNF-treated retina and the fellow retina were compared by a paired Student's $t$ test. $N S$, Statistically not significant; ${ }^{* *} p<0.01$ $* * * p<0.001$. Error bars represent SEM.
Density of typel $\mathrm{TH}+$ cells

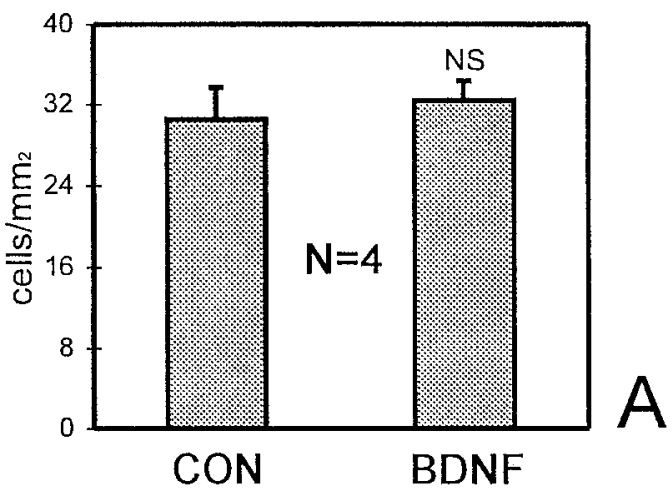

Density of typell $\mathrm{TH}+$ cells

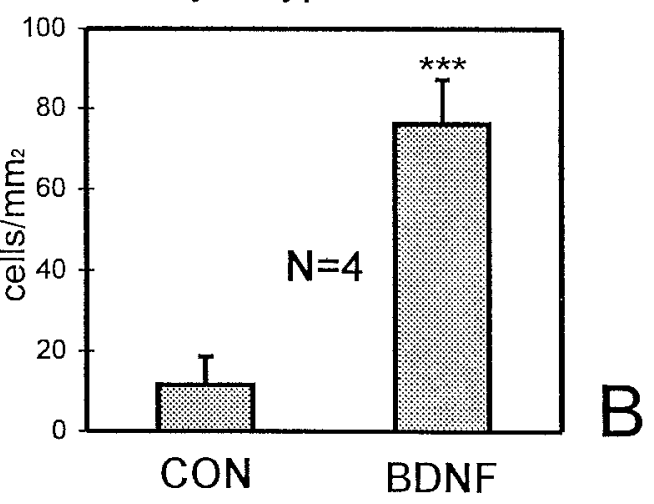

Size of typel TH+ cells

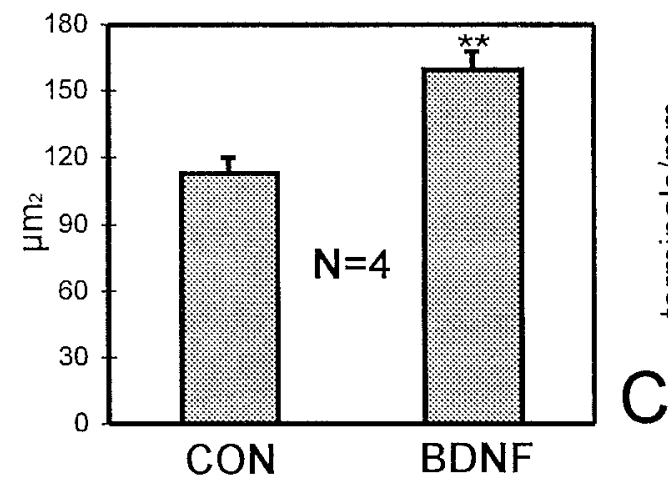

Density of $\mathrm{TH}+$ terminals

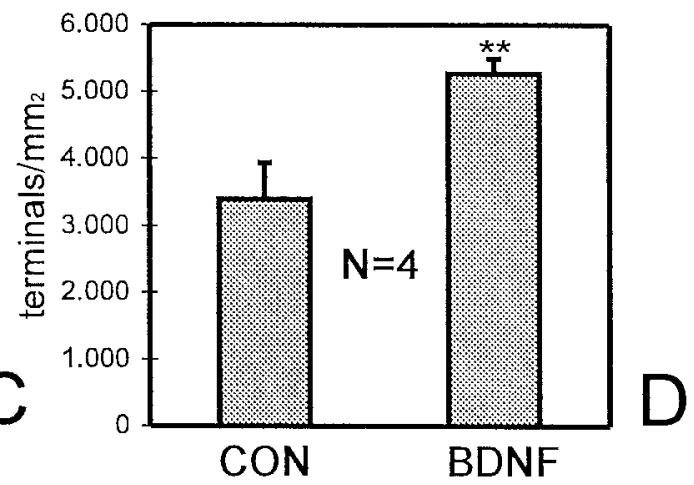

Retinae obtained from P20 bdnf+/- $(n=7), b d n f+/+(n=3)$, and $b d n f-/-$ mice $(n=5)$ were processed in parallel to allow comparison. P20 mouse retinae differed from age-matched rat retinae in that the density of type I dopaminergic neurons was more than double that of the rat, and the density of TH-positive varicosities was almost 10-fold higher (compare Fig. 5 and Fig. 8). However, the general organization of the dopaminergic system was otherwise similar between rats and mice. No type II cells were detected in mice.

No differences between $b d n f+/+$ and $b d n f+/-$ mice were noticed at a qualitative analysis. In contrast, the dopaminergic system was clearly altered in $b d n f-/-$ mice. The labeling of type I dopaminergic neurons was less intense, and the density of TH-positive varicosities was visibly reduced. A substantial variation in the intensity of TH immunolabeling and in the density of labeled varicosities was observed between the different $b d n f-/-$ mice. Because the intensity of TH immunolabeling varied little among different $b d n f+/+$ and $b d n f+/-$ mice, and retinae of all three different genotypes were dissected out and processed in parallel, a variability in the efficiency of immunolabeling can be excluded. The variability just mentioned thus likely reflects interindividual differences in phenotype expression.

Morphological parameters of TH-positive cells were quantified in the $b d n f+/+$ and $b d n f-/-$ mice. $b d n f+/-$ animals were not analyzed, because they did not visibly differ from wild-type controls. The number of TH-positive cells was slightly reduced in $b d n f-/-$ mice $(-31 \% ; p<0.05)$. The reduction in the number of type I dopaminergic neurons may have resulted from increased cell death or from failure to detect some faintly labeled neurons. The soma area of type I dopaminergic neurons was reduced by $22.5 \%(p<0.05)$, and the density of TH-positive varicosities was reduced by $57 \%(p<0.01)$ (Fig. 9). The densities of TH-positive varicosities were distributed with a much larger SD in the $b d n f-/-$ group than in the control group, probably as a consequence of the phenotype variability mentioned above.

\section{DISCUSSION}

The present study showed that intraocular injections of BDNF during the second or third postnatal week cause increased $\mathrm{TH}$ expression in retinal dopaminergic neurons, hypertrophy of retinal type I dopaminergic neurons, and increased density of $\mathrm{TH}$ positive varicosities in rats. On the other hand, in mice homozygous for a null mutation of the $b d n f$ gene, retinal dopaminergic neurons are atrophic and the density of TH-positive varicosities is reduced.

Upregulation of TH expression was observed also after injection of NT-3 and NT-4 but not NGF. The observation of more that one neurotrophin acting on the same neuron is not surprising: other CNS populations have had similar responsiveness (McAllister et al., 1995, 1997; Meyer-Franke et al., 1995; Oppenheim, 1996). The phenotype of $b d n f-/-$ mice clearly indicates that the effects of exogenously supplied BDNF reflect a physiological action. NT-4 may just activate TrkB that is present on these cells (Cellerino and Kohler, 1997), whereas the role of 

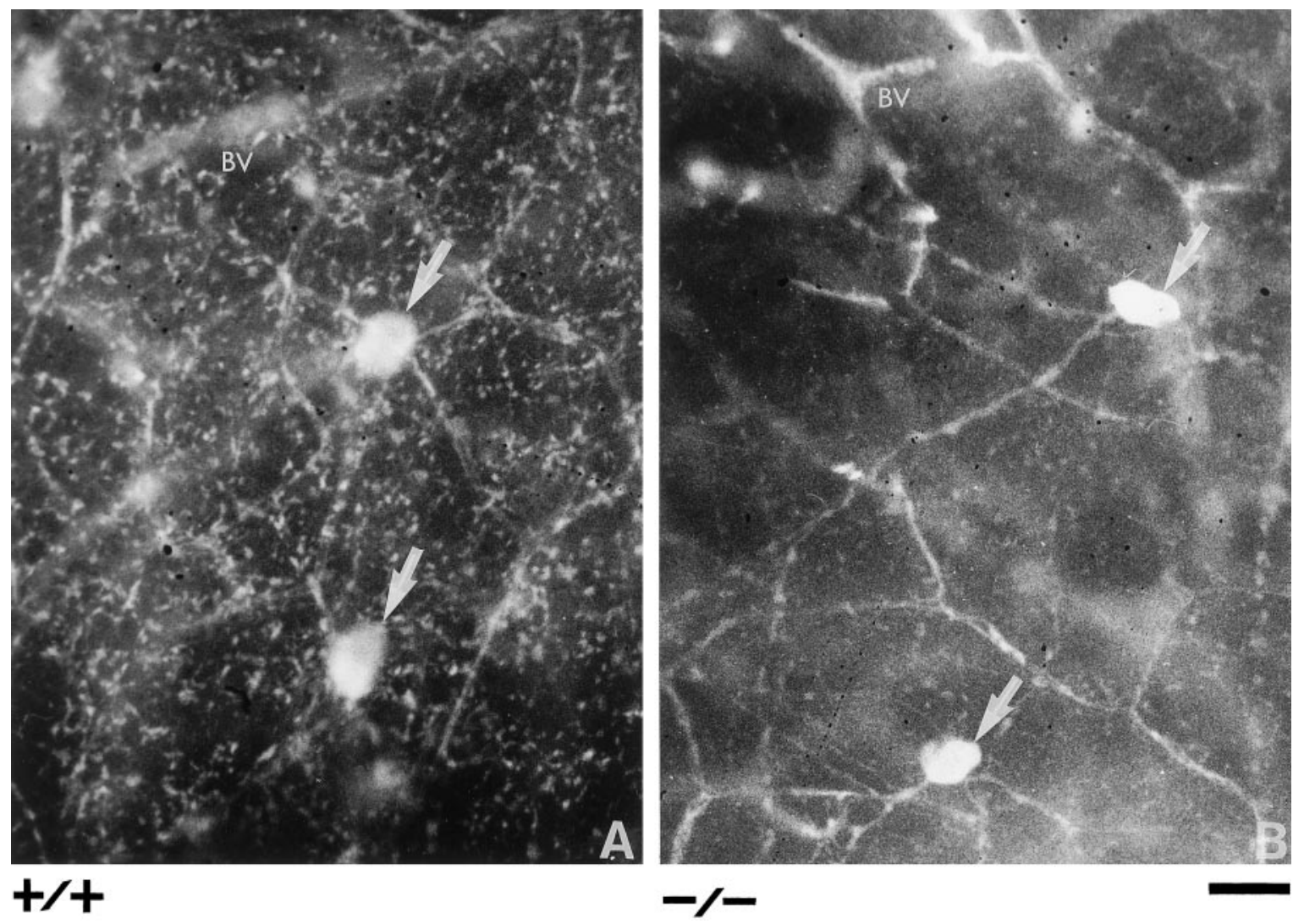

Figure 8. Pattern of dopaminergic innervation in P20 bdnf $+/+$ and $b d n f-/-$ mice. Focus at the level of stratum 1, central retina. The cell bodies of TH-positive cells are slightly out of focus. Secondary antibodies cross-reacted with endogenous mouse IgGs, resulting in labeling of blood vessels $(B V)$. Type I dopaminergic neurons are indicated by arrows. Scale bar, $22 \mu \mathrm{m}$.

NT-3 is less clear, and because data are lacking that refer to $n t-3-/-$ mice, a pharmacological action cannot be excluded. It is equally possible, however, that also under physiological conditions dopaminergic neurons respond to several factors and that removal of both NT-3 and BDNF would impair their development even more severely.

The effects of BDNF on the dopaminergic neurons in the substantia nigra are well known (Hyman et al., 1994). Retinal and nigral dopaminergic neurons have different embryonic origins, however, and it is interesting that BDNF acts similarly on both of these dopaminergic populations. An interesting characteristic of dopaminergic retinal neurons is their use of GABA as coneurotransmitter (Wässle and Chun, 1988); in this sense they are homologous to GABAergic interneurons. Subpopulations of GABAergic interneurons in the cortex and hippocampus express TrkB, respond to BDNF, and are affected in $b d n f-/-$ mice (Nawa et al., 1994; Cellerino et al., 1996) (for review, see Marty et al., 1997). Retinal dopaminergic neurons would then be similar to other, telencephalic populations of GABAergic cells in their trophic dependence.

BDNF is known to influence the expression of several phenotypic markers of CNS neurons (Jones et al., 1994; Nawa et al., 1994; Marty et al., 1996). In the retina, BDNF clearly increases the expression of $\mathrm{TH}$, an effect that is particularly visible in type II dopaminergic cells. All of the described effects (increased number of TH-positive varicosities in s1, increased TH labeling in s3) may have resulted from enhanced TH expression rather than from changes in the dopaminergic network. Two lines of evidence argue against this possibility. (1) The changes in $\mathrm{TH}$ immunore- activity are paralleled by changes in the distribution of D2 dopamine receptors, which are present as presynaptic autoreceptors on the processes of retinal dopaminergic neurons (Veruki, 1996). Because expression of these two proteins is likely to be regulated independently, concerted changes in their distribution are strongly indicative of corresponding physical changes in the dopaminergic network. (2) BDNF treatment dramatically increases the density of the TH-positive plexus in s3. When observed in flat mounts, these processes into $\mathrm{s} 3$ are seen to originate from type I dopaminergic neurons. The detailed morphology of type I dopaminergic neurons in normal animals is known from intracellular fillings (Voigt and Wässle, 1987; Dacey, 1990), and these cells extend only a few, if any, short processes into s3. For this reason, the profuse s3 labeling observed after BDNF treatment cannot be explained by upregulation of $\mathrm{TH}$ immunoreactivity in processes that are present, but not visible, in normal animals and must therefore be the result of sprouting.

Following these two lines of reasoning, it seems also likely that variations in the number of detectable $\mathrm{TH}$-positive varicosities in s1 are also attributable, at least in part, to changes in the physical density of the dopaminergic network.

These data would be in line with a recent report showing that the density of afferent innervation and the size of afferent preganglionic neurons in the sympathetic system are controlled by limited amounts of BDNF produced in their target, the sympathetic neurons (Causing et al., 1997). A further parallel between preganglionic neurons and retinal dopaminergic cells is that both neuronal populations are atrophic in $b d n f-/-$ mice and are hypertrophic if excess BDNF is present. 



Figure 9. Quantitative analysis of dopaminergic neurons in $b d n f+/+$ and $b d n f-/-$ mice at P20. $A$, Density of type I dopaminergic cells expressed as number of cells per square millimeter. See Materials and Methods for details of the sampling method. $+/+$ indicates $b d n f+/+$ mice, and $-/-$ indicates $b d n f-/-$ mice. $B$, Soma area of type I dopaminergic neurons. See Materials and Methods for details of the sampling method. $+/+$ indicates $b d n f+/+$ mice, and $-/-$ indicates $b d n f-/-$ mice. $C$, Density of TH-positive varicosities in stratum 1 of the inner plexiform layer expressed as number of varicosities per square millimeter. See Materials and Methods for details of the sampling method. $+/+$ indicates $b d n f+/+$ mice, and $-/-$ indicates $b d n f-/-$ mice. Data were analyzed using a two-tailed Student's $t$ test with independent variability in the two samples. Statistical significance is indicated as follows: * $p<$ $0.05, * *<0.01$. Error bars represent SEM.

It is a widely accepted view that the density of innervation of peripheral tissues is determined by the amount of target-derived neurotrophic factors. The seminal work of Purves and colleagues (1988) suggested that this concept could be extended to synapses in the nervous system. This view has been supported, although indirectly, by a subsequent series of studies showing effects of neurotrophins on activity-dependent synaptic plasticity (for review, see Lo, 1995; Thoenen, 1995; Bonhoeffer, 1996; Cellerino and Maffei, 1996). The data presented in this paper, combined with results obtained from studies of the sympathetic system (Causing et al., 1997) and the frog visual system (Cohen-Cory and Fraser, 1995), strengthen the hypothesis that the density of innervation in the CNS is controlled by limited amounts of neuron-derived neurotrophic factors.

If BDNF increases the density of dopaminergic innervation, it would be interesting to investigate the specificity of these connections. In the retina, various physiological and neurochemical pathways are segregated into different strata of the IPL. The anatomical segregation of the physiologically defined $\mathrm{ON}$ and OFF pathways requires afferent electrical activity (Bodnarenko et al., 1995). The mechanisms underlying the segregation of more finely restricted pathways are totally unknown. It is thus interesting to observe that BDNF, NT-3, and NT-4 all cause a more profuse dopaminergic innervation in $\mathrm{s} 1$ and $\mathrm{s} 3$ but not in other strata of the IPL. Because a sparse dopaminergic innervation is normally present in s3 (Nguyen-Legrós, 1988), sprouting after neurotrophin treatment occurs only in the strata where growth is permitted under normal conditions. In other words, if molecular cues (attractive/repulsive) are responsible for the radially restricted growth of dopaminergic fibers, this constraint cannot be overcome by neurotrophins. This is consistent with data obtained in the visual cortex and the retinotectal system showing that BDNF influences the tangential organization of afferents but does not perturb the lamina-specific pattern of innervation (Cabelli et al., 1995; Inoue and Sanes, 1996).

In adult mammals, dopaminergic innervation of $\mathrm{s} 1$ is organized into pericellular baskets, many of which are formed around the small-field, bistratified AII amacrine cells (Voigt and Wässle, 1987). It would interesting to investigate whether BDNF is required for the formation of this peculiar pattern of innervation and whether exogenous BDNF perturbs the specificity of these connections. Unfortunately, $b d n f-/-$ mice do not survive long enough to allow this analysis, whereas long-term BDNF treatment over several weeks cannot be obtained by repeated intraocular injections. Therefore, it is presently impossible to answer this interesting question.

Our data clearly indicate that BDNF is essential for the development of the retinal dopaminergic system. It remains to be 
determined which type of retinal cells provides BDNF to these neurons. BDNF is expressed by retinal ganglion cells in the rat (Peréz and Caminos, 1995), but dopaminergic amacrine neurons make no direct connections with retinal ganglion cells. The main target of dopaminergic cells is the AII amacrine cell. A low level of BDNF expression has been shown in the INL as well (Peréz and Caminos, 1995; Hallböök et al., 1996) (our unpublished observation), and it has been shown that retinal BDNF mRNA is not dramatically reduced when retinal ganglion cells are eliminated by section of the optic stalk (Herzog and von Bartheld, 1997). Dopaminergic neurons coexpress dopamine and GABA (Wässle and Chun, 1988) and either could obtain BDNF from their postsynaptic targets, as do GABAergic neurons in the visual cortex (Cellerino et al., 1996), or be involved in an autocrine loop, like midbrain dopaminergic neurons (Seroogy et al., 1994). In this context, it is of great interest that attenuation of trkB expression in vivo reduces the expression of parvalbumin in AII amacrine neurons (Rickman and Bowes-Rickman, 1996). The effects observed on AII amacrine cells may be secondary to changes in the dopaminergic network or vice versa. A detailed study of BDNF expression in dopaminergic neurons and AII amacrine cells is indispensable for examining this issue.

\section{REFERENCES}

Barbacid M (1994) The trk family of neurotrophin receptors. J Neurobiol 25:1386-1403.

Bodnarenko SR, Jeyarasasingam G, Chalupa LM (1995) Development and regulation of dendritic stratification in retinal ganglion cells by glutamate-mediated afferent activity. J Neurosci 15:7037-7045.

Bonhoeffer T (1996) Neurotrophins and activity-dependent development of the neocortex. Curr Opin Neurobiol 6:119-126.

Cabelli RJ, Hohn A, Shatz CJ (1995) Inhibition of ocular dominance column formation by infusion of NT-4/5 or BDNF. Science 267:1662-1666.

Cabelli RJ, Shelton DL, Segal RA, Schatz CJ (1997) Blockade of endogenous ligands of trkB inhibits formation of ocular dominance columns. Neuron 19:63-76.

Causing CG, Gloster A, Aloyz R, Bamji SX, Chang E, Fawsett J, Kuchel G, Miller FD (1997) Synaptic innervation density is regulated by neuron-derived BDNF. Neuron 18:257-267.

Cellerino A, Kohler K (1997) The brain-derived neurotrophic factor/ neurotrophin-4 receptor TrkB is localized on ganglion cells and dopaminergic amacrine cells in the vertebrate retina. J Comp Neurol 386:149-161.

Cellerino A, Maffei L (1996) The action of neurotrophins in the development and plasticity of the visual cortex. Prog Neurobiol 49:53-71.

Cellerino A, Maffei L, Domenici L (1996) The distribution of brainderived neurotrophic factor and its receptor trkB in parvalbumincontaining neurons of the rat visual cortex. Eur $\mathrm{J}$ Neurosci 8:1190-1197.

Cellerino A, Pinzón-Duarte G, Carroll P, Kohler K (1997) BDNF controls the development of dopaminergic innervation in the rodent retina. Soc Neurosci Abstr 23:124.4.

Cohen-Cory S, Fraser S (1995) Effects of brain-derived neurotrophic factor on optic axon branching and remodeling in vivo. Nature 378:192-196.

Dacey D (1990) The dopaminergic amacrine cell. J Comp Neurol 301:461-489.

Davies AM (1994) The role of neurotrophins in the developing nervous system. J Neurobiol 25:1334-1348.

Domenici L, Cellerino A, Berardi N, Cattaneo A, Maffei L (1994) Monoclonal antibodies to NGF prolong the sensitive period for monocular deprivation in the rat. NeuroReport 5:2041-2044.

Figurov A, Pozzo-Miler LD, Olafson P, Wang T, Lu B (1996) Regulation of synaptic responses to high-frequency stimulation and LTP by neurotrophins in the hippocampus. Nature 381:706-709.

Galuske RAW, Kim D-S, Castrén E, Thoenen H, Singer W (1996) Brain-derived neurotrophic factor reverses experience-dependent synaptic modifications in kitten visual cortex. Eur J Neurosci 8:1554-1559.
Gu Q, Liu Y, Cynader MS (1994) Nerve growth factor-induced ocular dominance plasticity in adult cat visual cortex. Proc Natl Acad Sci USA 9:8408-8412

Hallböök F, Bäackström A, Kullander K, Ebendal T, Carri NG (1996) Expression of neurotrophins and trk receptors in the avian retina. J Comp Neurol 364:664-676.

Herzog K-H, von Bartheld CS (1998) Contributions of the optic tectum and the retina as sources of brain-derived neurotrophic factor for retinal ganglion cells in the chick embryo. J Neurosci, in press.

Hokoç JN, Mariani AP (1987) Tyrosine hydroxylase immunoreactivity in the rhesus monkey retina reveals synapses from bipolar cells onto dopaminergic amacrine neurons. J Neurosci 7:2785-2793.

Horsburgh GM, Sefton AJ (1987) Cellular degeneration and synaptogenesis in the developing retina of the rat. J Comp Neurol 263:553-566.

Hyman C, Juhasz M, Jackson C, Wright P, Ip NY, Lindsay RM (1994) Overlapping and distinct actions of the neurotrophins BDNF, NT-3, and NT-4/5 on cultured dopaminergic and GABAergic neurons of the ventral mesencephalon. J Neurosci 14:335-347.

Ibañez CF (1994) Structure-function relationships in the neurotrophin family. J Neurobiol 25:1349-1361.

Inoue A, Sanes JR (1996) Lamina-specific connectivity in the brain: regulation by $\mathrm{N}$-caderin, neurotrophins and glycoconjugates. Science 276:1428-1431.

Jones KR, Farinas I, Backus C, Reichardt LF (1994) Targeted disruption of the BDNF gene perturbs brain and sensory neuron development but not motor neuron development. Cell 76:989-999.

Kang H, Schuman EM (1995) Long-lasting neurotrophin-induced enhancement of synaptic transmission in the adult hippocampus. Science 267:1658-1662.

Kolb H (1994) The architecture and functional circuits in the vertebrate retina. Invest Ophthalmol Vis Sci 35:2385-2404.

Korte M, Carroll P, Wolf E, Brem G, Thoenen H, Bonhoeffer T (1995) Hippocampal long-term potentiation is impaired in mice lacking brainderived neurotrophic factor. Proc Natl Acad Sci USA 92:8856-8860.

Korte M, Griesbeck O, Gravel C, Carroll P, Staiger V, Theonen H, Bonhoeffer T (1996) Virus-mediated gene transfer into hippocampal CA1 region restores long-term potentiation in brain-derived neurotrophic factor mutant mice. Proc Natl Acad Sci USA 93:12547-12552.

Le $\beta$ mann V, Gottmann K, Heumann R (1994) BDNF and NT-4/5 enhance glutamatergic transmission in cultured hippocampal neurones. NeuroReport 6:21-25.

Levine E, Dreyfus CF, Black I, Plummer MR (1995) Brain derived neurotrophic factor rapidly enhances synaptic transmission in hippocampal neurons via postsynaptic tyrosine kinase receptors. Proc Natl Acad Sci USA 92:8074-8077.

Lewin GR, Barde Y-A (1996) Physiology of neurotrophins. Annu Rev Neurosci 19:289-317.

Lo DC (1995) Neurotrophic factors and synaptic plasticity. Neuron 15:979-981.

Maffei L, Berardi N, Domenici L, Parisi V, Pizzorusso T (1992) Nerve growth factor (NGF) prevents the shift in ocular dominance distribution of visual cortical neurons in monocularly deprived rats. J Neurosci 12:4651-4662.

Mariani AP, Hokoç JN (1988) Two types of tyrosine hydroxylaseimmunoreactive amacrine cells in the rhesus monkey retina. J Comp Neurol 276:81-91.

Marty S, Carroll P, Cellerino A, Castren E, Staiger V, Thoenen H, Lindholm D (1996) Brain-derived neurotrophic factor promotes the differentiation of various hippocampal nonpyramidal neurons, including Cajal-Retzius cells, in organotypic slice cultures. J Neurosci 16:675-687.

Marty S, Berzaghi M, Berninger B (1997) Neurotrophins and activitydependent plasticity of cortical interneurons. Trends Neurosci 20:198-202.

McAllister KA, Lo DC, Katz LC (1995) Neurotrophins regulate dendritic growth in developing visual cortex. Neuron 15:791-803.

McAllister KA, Katz LC, Lo DC (1997) Opposing roles for endogenous BDNF and NT-3 in regulating cortical dendritic growth. Neuron 18:767-778.

Meyer-Franke A, Kaplan MR, Pfrieger FW, Barres BA (1995) Characterization of the signaling interactions that promote the survival and growth of developing retinal ganglion cells in culture. Neuron 15:805-819.

Mitrofanis J, Maslim J, Stone J (1988) Catecholaminergic and cholin- 
ergic neurons in the developing retina of the rat. J Comp Neurol 276:343-359.

Nawa H, Pellymounter MA, Carnahan J (1994) Intraventricular administration of $\mathrm{BDNF}$ increases neuropeptide expression in newborn rat brain. J Neurosci 14:3751-3765.

Nguyen-Legrós J (1988) Morphology and distribution of catecholamineneurons in mammalian retina. Prog Ret Res 7:114-147.

Nguyen-Legrós J, Vigny A, Gay M (1983) Postnatal development of TH-like immunoreactivity in the rat retina. Exp Eye Res 37:23-32.

Oppenheim RW (1996) Neurotrophic survival molecules for motoneurons: an embarrassment of riches. Neuron 17:195-197.

Patterson SL, Abel T, Deuel TA, Martin KC, Rose JC, Kandel ER (1996) Recombinant BDNF rescues deficits in basal synaptic transmission and hippocampal LTP in BDNF knockout mice. Neuron 16:1137-1145.

Peréz MTR, Caminos E (1995) Expression of brain-derived neurotrophic factor and its functional receptor in neonatal and adult rat retina. Neurosci Lett 183:96-99.

Purves D, Snider WD, Voyvodic JT (1988) Trophic regulation of nerve cell morphology and innervation in the autonomic nervous system. Nature 336:123-128.

Rickman DW, Bowes-Rickman C (1996) Suppression of the trk-B expression by antisense oligonucleotides alters a neuronal phenotype in the rod pathway of the developing rat retina. Proc Natl Acad Sci USA 93:12564-12569.

Seroogy KB, Lundgren KH, Tron TM, Guthrie KM, Isackson PJ, Gall CM (1994) Dopaminergic neurons in rat ventral midbrain express brain-derived neurotrophic factor and neurotrophin-3 mRNA. J Comp Neurol 342:321-334.

Snider WD (1994) Functions of the neurotrophins during nervous system development: what the knock-outs are teaching us. Cell 77:627-638

Sterling P (1990) Retina. In: The synaptic organization of the brain (Shepherd GM, ed), pp 170-213. Oxford: Oxford UP.

Thoenen H (1995) Neurotrophins and neuronal plasticity. Science 270:593-597.

Versaux-Botteri C, Nguyen-Legrós J (1986) An improved method for tyrosine-hydroxylase immunolabeling of catecholamine cells in wholemounted rat retina. J Histochem Cytochem 34:734-748.

Veruki ML (1996) Dopaminergic neurons in the rat retina express dopamine D2/3 receptors. Eur J Neurosci 9:1096-1100.

Voigt T, Wässle H (1987) Dopaminergic innervation of AII amacrine cells in the mammalian retina. $\mathrm{J}$ Neurosci 7:4115-4128,

Wässle H, Boycott BB (1991) Functional architecture of the mammalian retina. Physiol Rev 71:447-480.

Wässle H, Chun MH (1988) Dopaminergic and indoleamineaccumulating amacrine cells express GABA-like immunoreactivity in the cat retina. J Neurosci 8:3383-3394.

Witkowsky P, Dearry A (1991) Functional roles of dopamine in the vertebrate retina. Prog Ret Res 11:247-292.

Witkowsky P, Schütte M (1991) The organization of dopaminergic neurons in vertebrate retinas. Vis Neurosci 7:113-124. 